\title{
Resistance to venetoclax and hypomethylating agents in acute myeloid leukemia
}

\author{
Antoine N. Saliba ${ }^{1}$, August J. John², Scott H. Kaufmann ${ }^{1,2,3}$ \\ 'Division of Hematology, Department of Medicine, Mayo Clinic, Rochester, MN 55905, USA. \\ 2Department of Molecular Pharmacology and Experimental Therapeutics, Mayo Clinic, Rochester, MN 55905, USA. \\ ${ }^{3}$ Division of Oncology Research, Department of Oncology, Mayo Clinic, Rochester, MN 55905, USA.
}

Correspondence to: Dr. Antoine N. Saliba and Scott H. Kaufmann, Division of Oncology Research, Gonda 19-212, Mayo Clinic, 200 First St., S.W., Rochster, MN 55905, USA. E-mails: Saliba.Antoine@mayo.edu; Kaufmann.Scott@mayo.edu

How to cite this article: Saliba AN, John AJ, Kaufmann SH. Resistance to venetoclax and hypomethylating agents in acute myeloid leukemia. Cancer Drug Resist 2021;4:125-42. http://dx.doi.org/10.20517/cdr.2020.95

Received: 18 Oct 2020 First Decision: 6 Nov 2020 Revised: 12 Nov 2020 Accepted: 16 Nov 2020 Available online: 19 Mar 2021

Academic Editor: Robert C. A. M. van Waardenburg Copy Editor: Cai-Hong Wang Production Editor: Jing Yu

\begin{abstract}
Despite the success of the combination of venetoclax with the hypomethylating agents (HMA) decitabine or azacitidine in inducing remission in older, previously untreated patients with acute myeloid leukemia (AML), resistance - primary or secondary - still constitutes a significant roadblock in the quest to prolong the duration of response. Here we review the proposed and proven mechanisms of resistance to venetoclax monotherapy, HMA monotherapy, and the doublet of venetoclax and HMA for the treatment of AML. We approach the mechanisms of resistance to HMAs and venetoclax in the light of the agents' mechanisms of action. We briefly describe potential therapeutic strategies to circumvent resistance to this promising combination, including alternative scheduling or the addition of other agents to the HMA and venetoclax backbone. Understanding the mechanisms of action and evolving resistance in AML remains a priority in order to maximize the benefit from novel drugs and combinations, identify new therapeutic targets, define potential prognostic markers, and avoid treatment failure.
\end{abstract}

Keywords: Venetoclax, hypomethylating agents, resistance, acute myeloid leukemia, azacitidine, decitabine

\section{INTRODUCTION}

Acute myeloid leukemia (AML) is a heterogeneous disease with diverse molecular profiles, clinical outcomes, and disease-specific mortality. In 2020, there will be an estimated 20,000 new cases of AML and 11,200 deaths due to the disease in the U.S. ${ }^{[1]}$. For decades, the cornerstone of treatment for primary AML

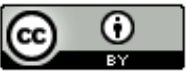

(C) The Author(s) 2021. Open Access This article is licensed under a Creative Commons Attribution 4.0 International License (https://creativecommons.org/licenses/by/4.0/), which permits unrestricted use, sharing, adaptation, distribution and reproduction in any medium or format, for any purpose, even commercially, as long as you give appropriate credit to the original author(s) and the source, provide a link to the Creative Commons license, and indicate if changes were made.

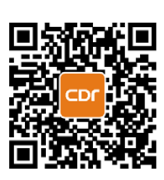


has been induction therapy with cytarabine and an anthracycline followed by consolidation with high-dose cytarabine chemotherapy or hematopoietic stem cell transplant (HSCT). Most patients with AML respond to initial induction chemotherapy and achieve a complete remission (CR), with rates ranging between 40 and $90 \%$ in different studies ${ }^{[2-5]}$. However, long-term survival rates remain significantly lower at about $40 \%-50 \%$ for adults younger than 60 years of age and less than $10 \%$ in adults age 60 years and older ${ }^{[5,6]}$. The high rate of relapse in older patients has been attributed to several factors, including lower tolerance to chemotherapy, poor performance status, comorbid diseases, a higher incidence of secondary AML, a higher incidence of adverse karyotypes, and acquired drug resistance ${ }^{[7,8]}$. In addition, $20 \%$ of patients treated with standard chemotherapy experience primary induction failure ${ }^{[9,10]}$. Therefore, mechanisms of de novo and acquired resistance to chemotherapy remain central barriers to achieving long-term remission.

The biological basis for this therapy resistance has been extensively studied. Certain cytogenetic abnormalities and genetic mutations are predictive of clinical course, prognosis, and response to conventional chemotherapy or more novel targeted therapies ${ }^{[11-14]}$. For instance, the presence of the genetic abnormalities $t(8 ; 21)$ or $\operatorname{inv}(16) / t(16 ; 16)$ is associated with a high rate of response to conventional combination chemotherapy and a favorable prognosis ${ }^{[3,1]}$. Conversely, a complex karyotype or aneuploidy is associated with resistance to chemotherapy and a poor prognosis ${ }^{[6,11]}$. Although the relatively high proportion of patients with cytogenetically normal AML limits the prognostic and clinical utility of these cytogenetically defined groups ${ }^{[1]]}$, recent advances in the understanding of the molecular landscape of AML have simultaneously expanded our prognostic ability and facilitated the development of agents targeting specific actionable alterations, including mutations of fms-like tyrosine kinase 3 (FLT3) and isocitrate dehydrogenase 1 and 2 (IDH1 and IDH2) ${ }^{[15-17]}$. Agents that target these abnormalities, including IDH inhibitors (e.g., ivosidenib and enasidenib), FLT3 inhibitors (e.g., midostaurin, gilteritinib, quizartinib, and sorafenib), and others, have offered an opportunity for remission with AML harboring targetable mutations ${ }^{[17,18]}$. Because targetable genetic mutations are found in only a minority of patients with AML, the parallel introduction of apoptosis-inducing therapies has shown promise in overcoming conventional chemotherapy resistance and can be used irrespective of the genetic signature ${ }^{[19,20]}$.

The "hypomethylating agents" (HMAs) azacitidine (5-azacitidine) and decitabine (5-aza-2'-deoxycytidine) are nucleoside derivatives that are incorporated into DNA, where they inhibit DNA methyltransferases (DNMT). HMAs have been primarily used to treat AML patients who are 60 years of age and older or those who are unable to withstand the rigors of conventional chemotherapy. In comparison to conventional combination chemotherapy, single-agent HMA or low-dose cytarabine (LDAC) regimens are usually better tolerated and are associated with lower rates of treatment-related mortality ${ }^{[21]}$. However, response rates to HMAs alone are low (10\%-50\%), with a median survival of about 6-10 months ${ }^{[21-25]}$. The observation that antiapoptotic proteins, including BCL2, BCLX ${ }_{\mathrm{L}}$, and MCL1, are frequently overexpressed in AML and are associated with resistance to chemotherapy, eventually led to the addition of venetoclax, an oral selective small molecule inhibitor of BCL2, to LDAC or HMA therapy, initially in older adults with primary or secondary AML who were ineligible for conventional chemotherapy ${ }^{[26]}$. Rates of CR or CR with incomplete hematologic recovery (CRi) were 54\% for the LDAC/venetoclax regimen and $67 \%$ for the HMA/venetoclax doublet, with a significant extension in overall survival (OS) to a median of 10-18 months ${ }^{[27]}$. These findings were more recently confirmed by the results of the phase III randomized placebo-controlled trial showing superiority of the combination of azacitidine and venetoclax over single-agent azacitidine in a group of previously untreated patients with AML who were not eligible for standard induction chemotherapy ${ }^{[28]}$. With a CR/CRi rate of $66 \%$ in the azacitidine/venetoclax group vs. $28 \%$ in the control group, a significant prolongation in median OS was achieved (14.7 months $v s .9 .6$ months respectively ${ }^{[28]}$.

Despite these promising results, about half of the responders to azacitidine/venetoclax relapse after a median duration of about 18 months ${ }^{[28]}$. Therefore, although the last few years have witnessed important 


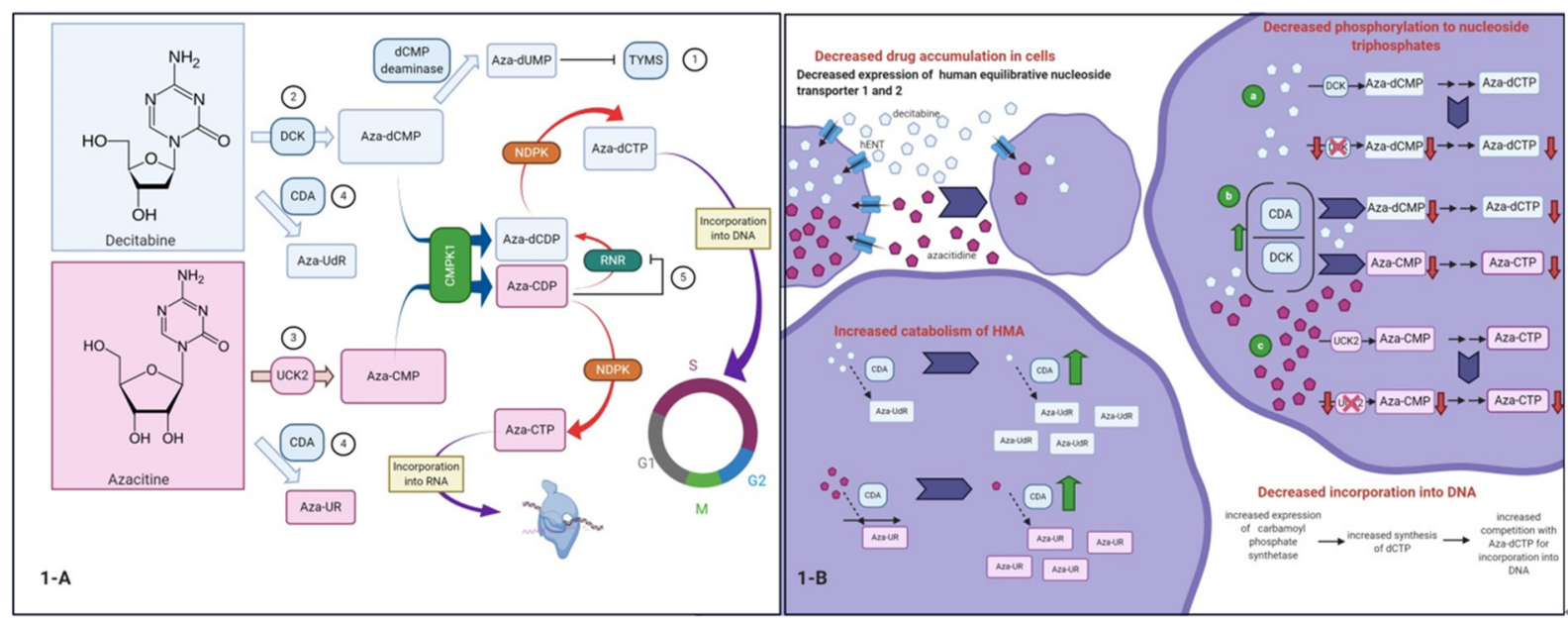

Figure 1. Proposed mechanisms of auto-resistance to hypomethylating agents ${ }^{[35]}$. A: mechanisms related to changes in nucleoside metabolism: (1) decitabine inhibits thymidylate synthase (TYMS). As a consequence dTTP levels decrease and dCTP levels increase. This is associated with a (2) decrease in deoxycytidine kinase (DCK), (3) increase in uridine/cytidine kinase 2 (UCK2), and (4) increase in cytidine deaminase (CDA). Alternatively, azacitidine is metabolized to aza-CDP, which (5) inhibits ribonucleotide reductase (RRM1). Inhibition of ribonucleotide reductase diminishes the conversion of aza-CDP to aza-dCDP and eventually aza-dCTP, which is capable of depleting DNMT1. In addition, dCTP levels decrease and, subsequently, $(2,4)$ DCK and CDA increase while (3) UCK2 decreases, which in turn decreases the conversion of azacitidine to aza-CMP; B: additional mechanisms of resistance. Decreased expression of human equilibrative nucleoside transporter (hENT) 1 and 2 is associated with decreased intracellular accumulation of decitabine and azacitidine. Although not a universal finding, a possible mechanism of resistance in MDS is an increase in carbamoyl-phosphate synthetase (CAD) expression, resulting in increased synthesis of dCTP, which competes with aza-dCTP for incorporation into DNA. CMPK: cytosine nucleoside monophosphate kinase; RNR: ribonucleotide reductase; NDPK: nucleoside diphosphate kinase. Figure was created with BioRender

advances in the treatment of AML, drug resistance continues to be an important clinical problem. As the armamentarium of therapeutic options continues to expand with agents, like the Nedd8 activating enzyme (NAE) inhibitors (e.g., pevonedistat) and the mouse double minute 2 homolog protein (MDM2) inhibitor KRT-232, being added to the HMA/venetoclax backbone, understanding the mechanisms of action and evolving resistance remains crucial in order to maximize the benefit from emerging drugs and combinations, identify new potential therapeutic targets, and determine potential prognostic markers. Hence, we review the individual actions of the HMAs and venetoclax as well as their individual mechanisms of resistance, and we then focus on potential mechanisms of resistance to the HMA/ venetoclax combination.

\section{HYPOMETHYLATING AGENTS}

\section{Mechanisms of action}

The HMAs azacitidine and decitabine constitute the backbone of treatment of high-risk myelodysplastic syndromes (MDS) and chronic myelomonocytic leukemia (CMML) $)^{[29-32]}$. Whether used as single agents or, more recently, in combination with venetoclax, HMAs have shown clinical activity in patients with primary, secondary, and relapsed/refractory $\mathrm{AML}^{[19,28,33]}$.

HMAs are pyrimidine analogs of the nucleoside cytidine that showed promising cytostatic activity at higher doses in the $1960 \mathrm{~s}^{[34]}$. In both azacitidine and decitabine, a nitrogen atom replaces a carbon atom in position 5 of the pyrimidine ring [Figure 1], but the sugar moiety is deoxyribose in decitabine and ribose in azacitidine ${ }^{[35]}$. There is evidence to support a dual mechanism of action for these agents: (1) a direct cytotoxic effect at higher doses, where the formation of covalent DNMT-DNA adducts leads to DNA damage; and (2) DNA hypomethylation and epigenetic modulation at lower doses with subsequent cell differentiation and tumor suppression ${ }^{[36,37]}$. 
One of the ways HMAs exhibit their action is through epigenetic mechanisms ${ }^{[38]}$. The role of DNA methylation, specifically cytosine methylation, in the control of gene expression and epigenetic regulation was identified in different eukaryotic cells in the $1970 \mathrm{~s}^{[39-41]}$. It was consequently thought that compounds capable of changing the patterns of cytosine methylation might impact cell differentiation and differential gene expression in various cell types that harbor the same genetic information. Azacitidine and decitabine were subsequently shown to alter differentiation in cultured mouse embryo cells ${ }^{[42-44]}$. Therefore, the focus with the use of HMAs shifted from their cytostatic and cytotoxic effects seen at higher doses to their role as potent inhibitors of DNA methylation at lower doses and with longer exposure ${ }^{[45]}$. Importantly, at these low doses, HMAs reportedly do not cause cell cycle arrest ${ }^{[46]}$.

Azacitidine and decitabine are prodrugs that require phosphorylation to monophosphate forms by uridine-cytidine kinase (UCK) and deoxycytidine kinase (DCK), respectively ${ }^{[38,47]}$. They are then further phosphorylated to diphosphate and triphosphate derivatives (5-aza-CTP and 5-aza-dCTP) by pyrimidine monophosphate and diphosphate kinases. These cytosine derivatives, like their natural counterparts, are also subject to degradation by cytidine deaminase (CDA).

The fates of 5-aza-CTP and 5-aza-dCTP are somewhat different. Approximately $80 \%-90 \%$ of azacitidine incorporates into RNA as 5-aza-CTP, resulting in alteration of RNA methylation and inhibition of protein synthesis $^{[48]}$. The RNA-dependent effects of azacitidine are independent of the cell cycle and affect both messenger and transfer $\mathrm{RNA}^{[49-51]}$. The remaining $10 \%-20 \%$ of azacitidine is converted to 5 -aza-dCTP by ribonucleotide reductase and, like the 5 -aza-dCTP that is the main metabolite of decitabine, is incorporated into DNA.

Once 5-aza-cytosine (5-aza-C) is incorporated into DNA, the downstream effects are the same whether the altered base is derived from azacitidine or decitabine. When DNMTs act on normal cytosine, they form a transient covalent bond between a cysteine at the enzyme active site and C6 of cytosine. When these same enzymes act on 5 -aza- $\mathrm{C}$, the same covalent adduct is formed, but it is more stable and cannot be enzymatically reversed. As a result, cells are left without the enzymatic activity of the adducted DNMT enzyme molecule and with a new covalent DNA-protein crosslink for each DNMT molecule inhibited ${ }^{[52-59]}$. Thus, after HMA treatment, formation of DNA-protein cross-links and loss of DNMT activity are inextricably linked.

According to current understanding, HMA-induced hypomethylation of promoters of tumor suppressor genes leads to the interruption of feedback loops between DNA methylation and histone methylation. This reverses the silenced chromatin state of the histones at the tumor suppressor genes, thus facilitating their expression, the resulting suppression of leukemogenesis, and the induction of cellular differentiation ${ }^{[45,60,61]}$.

HMAs also trigger DNA damage response pathways. At high HMA concentrations, phosphorylation of histone H2A.x is observed ${ }^{[62]}$, indicating that one or more of the DNA damage-activated kinases ATM, ATR or DNA-PK have been activated. The irreversibly bound DNMT can also lead to cell cycle arrest at the transition from S to G2 through the activation of the ATM and ATR pathways ${ }^{[63]}$. The events that occur downstream of cell cycle arrest and lead to removal of the DNA-DNMT protein cross-links are still being elucidated ${ }^{[64]}$. Current understanding, enhanced by the recent demonstration of DNMT inhibitor/PARP inhibitor synergy ${ }^{[62]}$, suggests that DNMT-DNA covalent complexes might be removed by base excision repair, although the glycolyase involved and how it is activated remain to be determined. Inhibition of DNMT1 may also indirectly affect DNA repair mechanisms ${ }^{[65,66]}$. Vispé et al. ${ }^{[67]}$ showed that combining treatment with decitabine and DNMT1 siRNA uncouples DNA damage from DNA demethylation and again suggests a dual mechanism of action for HMAs. 


\section{Activity of hypomethylating agents in myelodysplastic syndrome and AML}

HMAs have been used for the treatment of myeloid malignancies for more than a decade. The role of HMAs is currently expanding across wider age groups for various therapeutic indications (including preemptive and maintenance therapies), in novel formulations (including oral), and in combination with multiple other agents (including venetoclax, lenalidomide, and IDH inhibitors) ${ }^{[15,33,68-72]}$. The initial observation that a variety of tumor suppressor genes are silenced as a consequence of promoter hypermethylation in MDS and AML prompted the investigation of HMAs as epigenetic drugs in these hematological diseases ${ }^{[73]}$. When initially tested in phase I studies in AML at higher doses $\left(1500-2500 \mathrm{mg} / \mathrm{m}^{2}\right.$ of decitabine per course), HMAs caused prolonged and dose-limiting myelosuppression with overall response rates of 30\%$60 \%{ }^{[74,75]}$. The mechanism of action at those higher doses was thought to reflect formation of DNA-protein cross-links, activation of the DNA damage response, and direct cytotoxicity. Lower doses of decitabine (45 $\mathrm{mg} / \mathrm{m}^{2} /$ day, every $8 \mathrm{~h}$, for 3 consecutive days, every 6 weeks) were subsequently found to have an overall response rate of $49 \%$ in patients with high-risk MDS in phase II studies ${ }^{[76,77]}$. Subsequent phase III studies confirmed the clinical effectiveness of decitabine in the treatment of patients with MDS, with an overall response rate of $73 \%$ with decitabine $v s$. $0 \%$ with supportive care in the initial phase III trial ${ }^{[78]}$, and $54 \%$ with decitabine in a follow-up phase II trial in elderly patients with intermediate- or high-risk MDS ${ }^{[79]}$. Additional randomized trials have also shown a survival advantage in patients receiving azacitidine, with a median survival of 18 months in the azacitidine arm $v s .11$ months in the supportive care arm in the Cancer and Leukemia Group B (CALGB) 9221 trial $^{[80]}$, and 24.5 months vs. 15 months in patients with intermediate-2- or high-risk MDS in the AZA-001 trial ${ }^{[32]}$.

As indicated earlier in the Introduction, HMAs are also used to treat AML. Azacitidine monotherapy was first evaluated at $150-200 \mathrm{mg} / \mathrm{m}^{2} /$ day for five days in phase I and II studies in the pediatric patient population with AML and acute lymphoblastic leukemia ${ }^{[81]}$. Six out of the 14 patients with refractory AML achieved remission, but prolonged marrow suppression was a significant adverse event ${ }^{[81]}$. Prolonged myelosuppression was also dose limiting in a study of 154 adult patients with refractory AML treated with $150-700 \mathrm{mg} / \mathrm{m}^{2} /$ day for 1-7 days ${ }^{[82]}$. After a hiatus of several decades, decitabine and azacitidine were studied again in patients with AML, but at the lower doses that proved effective in MDS. In the AZA-001 trial, analysis of outcomes in a subgroup of patients with $20 \%-30 \%$ bone marrow blasts, who were originally classified as RAEB-t (i.e., refractory anemia with excess blasts in transformation) and subsequently considered as AML by the 2000 World Health Organization classification ${ }^{[83,84]}$, indicated prolonged median overall survival with azacitidine (24.5 months) compared to conventional care regimens such as LDAC, conventional chemotherapy, or best supportive care $(16.0 \text { months })^{[83]}$. An analysis of three CALGB trials with azacitidine $75 \mathrm{mg} / \mathrm{m}^{2} /$ day for seven days every 28 days by intravenous (CALGB 8421) or subcutaneous routes (CALGB 8921 and CALGB 9221) showed an overall response rates of 36\%-48\% and median survival of 19.3 months in the azacitidine group compared to 12.9 months for the observation group ${ }^{[85]}$. Retrospective data from European registries showed median overall survival estimates of 9-10 months ${ }^{[86,87]}$. A large phase III study, AZA-AML-001, randomized patients older than 65 years and with $>30 \%$ bone marrow blast counts to azacitidine $\left(75 \mathrm{mg} / \mathrm{m}^{2} /\right.$ day subcutaneously for 7 days every 28 days) or conventional care regimens ${ }^{[22]}$. Although there was no statistically significant difference in survival in the overall study population (10.4 months for azacitidine vs. 6.5 months for conventional care), survival was significantly prolonged in the subgroups with poor-risk cytogenetics or AML with myelodysplasia-related changes ${ }^{[22]}$, leading to the European Medicines Agency approval of azacitidine for the treatment of AML in adults above 65 years of age ${ }^{[22]}$. A phase III study (DACO-16) that randomized 485 patients age 65 years or older to decitabine $\left(20 \mathrm{mg} / \mathrm{m}^{2} /\right.$ day intravenously for 5 days every 28 days) or conventional care regimens (supportive care or LDAC) likewise failed to show a significant improvement in the primary endpoint of overall survival (7.7 months vs. 5.0 months, respectively) but showed a higher rate of CR/CRp (CR with incomplete platelet recovery) with decitabine ( $17.8 \%$ vs. $7.8 \%$, respectively; $P=0.001)^{[24]}$, leading to approval of single-agent decitabine for the treatment of AML in the older adults in Europe. More recently, 
the U.S. Food and Drug Administration (FDA) in September 2020 approved once-daily oral azacitidine as maintenance therapy for the continued treatment of AML in adults who achieve their first CR/CRi with induction chemotherapy and are not candidates for further intensive consolidation therapy with $\mathrm{HSCT}^{[71,72]}$.

A common theme across the clinical trials of HMAs in AML is a consistent trend towards improved survival despite the low CR rates of $<20 \%$. This led to a number of studies examining the impact of adding various agents to HMAs, ultimately resulting in the HMA/venetoclax regimen described in a subsequent section of this review.

\section{Mechanisms of resistance to hypomethylating agents}

When HMAs are used as single agents in myeloid malignancies, rates of remission are low, and durations of response are often short. Resistance, whether primary or secondary, is a central challenge in the treatment of MDS and AML. Therefore, potential mechanisms of resistance to HMAs have been extensively investigated. In brief, for HMAs to be active, they must accumulate in cells, undergo phosphorylation to the nucleoside triphosphates, avoid metabolic inactivation, and get incorporated into DNA. Resistance has been observed at each of these steps.

Resistance to HMAs can be mediated by membrane proteins that are involved in drug uptake. Human equilibrative nucleoside transporter-1 (hENT1) facilitates transport of nucleosides, including decitabine and azacitidine, in a bidirectional manner across the cell membran ${ }^{[88]}$. Consistent with a role for hENT1 in HMA cellular uptake, the level of hENT1 mRNA expression is significantly higher in patients who respond to decitabine ${ }^{[89]}$. Interestingly, the decreased activity of azacitidine in cells with low hENT activity can be overcome by the use of an elaic ester of azacitidine, CP-4200, with reduced dependence on membrane transporters $^{[90]}$.

The balance between HMA phosphorylation and enzymatic inactivation also plays a role in response. Cell lines that are resistant to decitabine have not only low expression of hENT1 and hENT2 but also low expression of DCK and high expression of $\mathrm{CDA}^{[36,89]}$. Both of these changes are thought to play a role in HMA resistance. Low expression of DCK diminishes the activating phosphorylation of decitabine, and high CDA results in rapid catabolism of decitabine and azacitidine to uridine counterparts that do not contribute to DNMT inhibition ${ }^{[91,92]}$. Consistent with these observations, malignant cell lines engineered to overexpress CDA are decitabine resistant. Azacitidine and decitabine have poor oral availability, likely reflecting high CDA expression in gastrointestinal and liver cells ${ }^{[91,93,94]}$.

In the clinical setting, it has been reported that lower expression of UCK1 is associated with blunted response to azacitidine ${ }^{[95]}$ and that DCK is significantly reduced in the bone marrow and peripheral blood specimens from MDS patients who relapsed after decitabine ${ }^{[89]}$, highlighting the importance of metabolic activation in the action of HMAs. These findings, however, have been far from universal. It has also been reported that expression of DCK or CDA does not distinguish MDS cases that respond to decitabine from those that do not, but the ratio of CDA to DCK was elevated in nonresponding cases ${ }^{[96]}$.

Emerging evidence suggests that metabolism of pyrimidines, including HMAs, reflects an adaptive network of enzymes that detect nucleotide levels and respond in a compensatory manner [Figure 1] ${ }^{[35]}$. For example, DCK protein is diminished in MDS samples with decitabine resistance and upregulated in azacitidineresistant cells. Conversely, UCK2 protein is upregulated in decitabine-resistant cells and diminished in azacitidine-resistant cells ${ }^{[35]}$. These observations raise the possibility of tailoring therapy based on DCK and UCK levels or diminishing HMA resistance by alternating HMAs ${ }^{[35,97]}$.

After HMAs are metabolically activated, they are incorporated into DNA in place of dCTP. The enzyme carbamoyl-phosphate synthetase (CAD) facilitates the synthesis of dCTP, which competes with aza-dCTP, 
for incorporation into DNA. Notably, CAD has been found to be upregulated in both cell lines and clinical MDS samples that are resistant to HMAs, although this has not been a universal finding ${ }^{[35,98,99]}$.

A number of additional determinants of response to HMAs have also been identified. Mutations in genes regulating methylation, including TET2, IDH1/2, and DNMT3A, have been associated with improved responses to HMAs in myeloid malignancies ${ }^{[100-104]}$, although this effect has not been universally observed. The variations in conclusions among studies have been attributed to an interaction between different mutations and disease heterogeneity, as suggested by the relationship between lower clonal burden of secondary mutations and higher response rate ${ }^{[105]}$.

As evidence of discordance between DNA methylation status and clinical response accumulated, the effects of HMAs on RNA were also explored ${ }^{[106]}$. About $90 \%$ of azacitidine is incorporated into RNA, raising the possibility that alterations in RNA metabolism might contribute to azacitidine action ${ }^{[107]}$. Consistent with this hypothesis, azacitidine response has been linked to NSUN1, an RNA:5-methylcytosine (m5C) methyltransferase that binds BRD4 and RNA-polymerase-II to form chromatin structures that are not sensitive to azacitidine ${ }^{[108]}$. Bone marrow specimens from patients with azacitidine-resistant AML or MDS showed a significant increase in RNA:m5C and NSUN1-/BRD4-associated active chromatin as compared to specimens from patients with sensitive $\mathrm{AML}$ or $\mathrm{MDS}^{[108]}$. This resistance mechanism is not applicable to decitabine, which contains 5-aza-cytosine bound to 2'-deoxyribose.

\section{VENETOCLAX}

\section{BCL2 family members and regulation of apoptosis}

Apoptosis is a regulated cell death process in eukaryotes that is activated by either extrinsic or intrinsic stimuli. Apoptosis mediates well-conserved decomposition of cellular macrostructures through activation of caspases, cysteine proteinases that cleave next to aspartate residues ${ }^{[109,110]}$. Within the intrinsic pathway of apoptosis, cell death is initiated by mitochondrial outer membrane permeabilization (MOMP) that facilitates the release of cytochrome $c$, formation of cytosolic apoptosome complexes, and subsequent caspase activation. The MOMP process is regulated by BCL2 family members, which dynamically modulate pro- and anti-apoptotic signaling ${ }^{[110,111]}$. Among the pro-apoptotic signaling proteins are BAK and BAX, which permeabilize the mitochondrial outer membrane upon activation ${ }^{[110-112]}$. These are in turn neutralized when they are bound and sequestered by the anti-apoptotic paralogs BCL2, BCLX ${ }_{L}$, MCL1, BCLW, BCLB, and BFL1 ${ }^{[110-113]}$. A third group of BCL2 family members called BH3-only proteins includes BID, BAD, BIK, BIM, PUMA, HRK, NOXA, and BMF, which act through competitive inhibition of the anti-apoptotic BCL2 family members, direct activation of BAK and BAX, or a combination of these two processes $^{[110-114]}$. Upregulation of anti-apoptotic signaling (e.g., through overexpression of BCL2 and its kin) has been implicated in the pathogenesis of cancer, particularly in hematopoietic malignancies, where the upregulation serves as both an essential hallmark of lymphoma- or leukemogenesis and a mechanism of drug resistance ${ }^{[115,116]}$. BCL2 is, therefore, an important therapeutic target for pharmacological inhibition in leukemia and other malignancies ${ }^{[177-120]}$.

\section{Action of single-agent venetoclax in hematological malignancies}

$\mathrm{BH} 3$ mimetics are small molecules that have been developed to overcome apoptosis resistance in various neoplasms. These agents were designed to specifically inhibit members of the anti-apoptotic pathway by mimicking the $\mathrm{BH} 3$ domain found in $\mathrm{BH} 3$-only proteins. Like these pro-apoptotic proteins, $\mathrm{BH}$-mimetics bind the $\mathrm{BH} 3$ binding groove of anti-apoptotic proteins, thereby inhibiting ability of anti-apoptotic family member to bind and neutralize BAX and/or BAK.

The first $\mathrm{BH} 3$ mimetic to enter clinical trials was navitoclax (ABT-263), which was designed to specifically mimic BAD binding to BCL2, BCLX $\mathrm{L}_{\mathrm{L}}$, and $\mathrm{BCLW}{ }^{[121]}$. Navitoclax showed efficacy in chronic 
lymphocytic leukemia (CLL) in early human studies ${ }^{[122]}$. However, navitoclax also displayed dose-limiting thrombocytopenia ${ }^{[123,124]}$ that was traced to involvement of $\mathrm{BCLX}_{\mathrm{L}}$ in platelet survival ${ }^{[125]}$. To avoid this toxicity, venetoclax was engineered to specifically inhibit BCL2 only ${ }^{[126]}$. Venetoclax sensitivity was shown to be BCL2-dependent, with decreased lethality in platelets and nanomolar potency in the BCL2-dependent disease CLL ${ }^{[122,126-128]}$.

As a $\mathrm{BH} 3$ mimetic, venetoclax is thought to act primarily by binding to $\mathrm{BCL} 2$, causing release of sequestered BAX and BAK, thereby leading to MOMP and apoptosis ${ }^{[117,119,129]}$. More specifically, venetoclax has been shown to form a hydrogen bond at Asp103 in BCL2 and interact with the intercalating indole on a partner BCL2 ${ }^{[126]}$. Alternatively, it has also been suggested that venetoclax might also lead to cell death by destabilizing the proton gradient across the mitochondrial inner membrane, leading to acidification of the cytosol and metabolic crisis ${ }^{[130]}$. Whatever the proximate action of venetoclax, the final outcome is MOMP and release of cytochrome $\mathrm{c}$ to the cytoplasm, thereby resulting in apoptosome formation as well as decreased ATP production due to diminished mitochondrial cytochrome $c^{[131,132]}$.

Biomarkers that predict response to venetoclax are not fully understood. Venetoclax was initially approved for the treatment of relapsed CLL with chromosome $17 \mathrm{p} \operatorname{loss}^{[122]}$. High BCL2 protein in this disease ${ }^{[133]}$, which results from deletion of genes encoding two microRNAs that target BCL2 mRNA ${ }^{[134,135]}$, was taken as a sign that CLL might be dependent on BCL2 for survival and, therefore, sensitive to BCL2 inhibition.

The correlation between high expression of BCL2 protein and sensitivity also appears to hold for other neoplasms, but this relationship can be lost when high levels of venetoclax-insensitive BCL2 paralogs such as MCL1 are expressed ${ }^{[166,136]}$. In secondary AML refractory to HMAs, an increase in BCL2 and/or BIM protein detected by immunohistochemistry in myeloblasts in pretreated bone marrow aspirates was strongly associated with venetoclax monotherapy response and overall survival ${ }^{[137]}$. In a phase II, singlearm clinical study of venetoclax monotherapy at a dose of $800 \mathrm{mg}$ daily in patients with relapsed/refractory AML or patients with previously untreated AML who were unfit for conventional chemotherapy, an objective response rate of 19\% (6 of 32 patients) was observed, with $6 \%$ (2 of 32 patients) achieving $\mathrm{CR}^{[138]}$. As described below, high expression of BCL2 relative to other anti-apoptotic BCL2 family members was associated with better outcomes.

\section{Mechanisms of resistance to venetoclax monotherapy}

Mechanisms of resistance in early trials of venetoclax in CLL were well studied ${ }^{[136,139-142]}$. De novo resistance was attributable to a lack of BCL2 dependence, either because BCL2 was not activated or the CLL depended upon other paralogs such as MCL1 or BCLX ${ }_{\mathrm{L}}^{[143-145]}$. Selection of cells that are dependent on an alternative BCL2 family member, such as $\mathrm{BCLX}_{\mathrm{L}}$ or MCL1, was also a major mechanism of acquired resistance [Figure 2] ${ }^{[14-148]}$.

This mechanism is not limited to CLL. Overexpression of MCL1 and/or BCLX $\mathrm{L}_{\mathrm{L}}$ may play a major role in the pathogenesis of various types of leukemia and mediate venetoclax resistance if BCL2 overexpression is not the primary antiapoptotic driver. In venetoclax-resistant AML cell lines, concurrent inhibition of MCL1 can mitigate venetoclax resistance ${ }^{[149-151]}$. Combining venetoclax with daunorubicin or cytarabine has been shown to reverse some of the BIM sequestration mediated by MCL1, also sensitizing AML to venetoclax ${ }^{[150]}$. In T-cell acute lymphoblastic leukemia cells with both MCL1 and BCL2 overexpression, combination therapy with inhibitors of both MCL1 (S63845) and BCL2 (venetoclax) is highly efficacious ${ }^{[152]}$.

A number of additional mechanisms of venetoclax resistance have been described. One involves the acquisition of mutations within BCL2 itself, such as the Gly101Val mutation, which prevents or reduces venetoclax binding ${ }^{[136,139-141,153]}$. Mutations in the transmembrane domain of BAX have also been shown to prevent mitochondrial anchoring of BAX, thereby preventing BAX from facilitating MOMP and inducing 


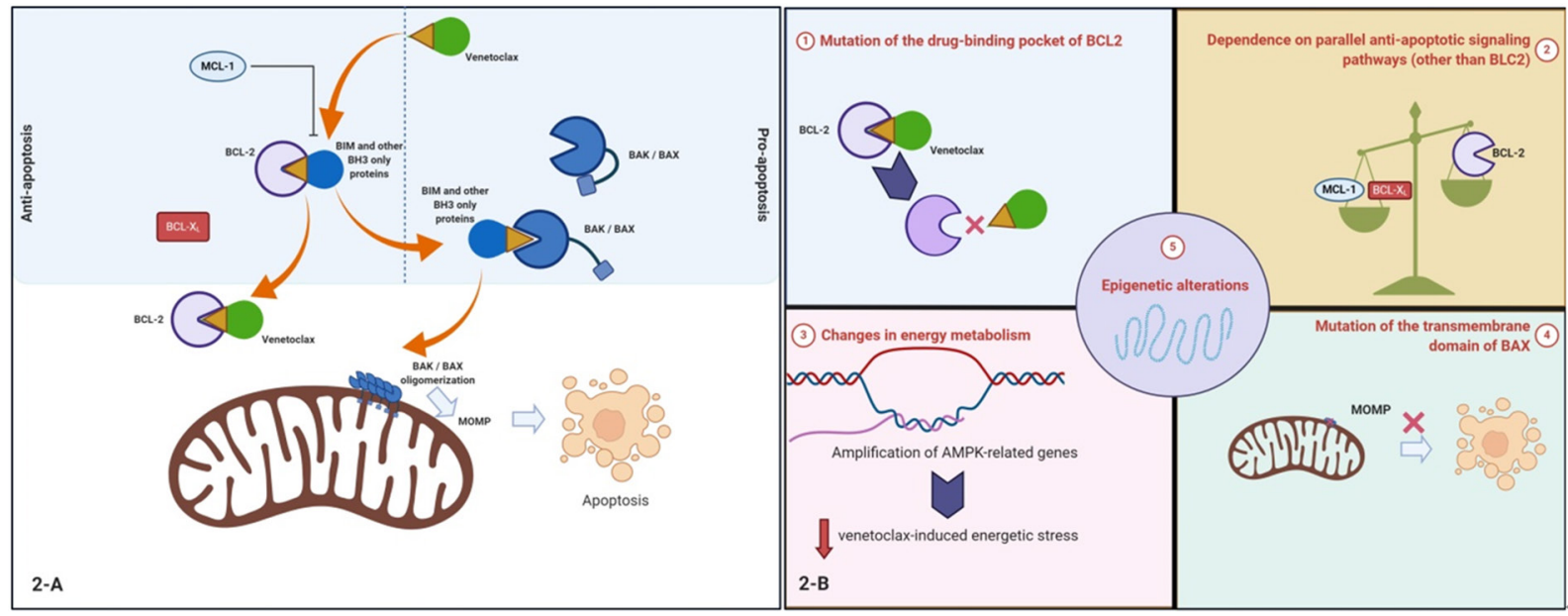

Figure 2. A: proposed mechanisms of resistance to venetoclax in acute myeloid leukemia (AML); B: see text for details: (1) mutations of direct drug-target binding pockets on BCL2. This proposed mechanism has been extrapolated from observations in chronic lymphocytic leukemia; (2) over-expression of MCL1 or BCLX can cause resistance. For instance, BIM that is released from BCL2 with venetoclax monotherapy can be sequestered by MCL1. This can be reversed by combining venetoclax with cytarabine or daunorubicin, which upregulates the MCL1 binding partner NOXA, or using a selective MCL1 inhibitor; (3) changes in energy metabolism. For instance, upregulation of fatty acid oxidation that may help provide metabolic plasticity to AML cells; (4) mutations of the transmembrane domain of BAX leading to a decrease in BAX-induced MOMP and apoptosis; (5) epigenetic alterations. For example, HOXA and HOXB genes are highly expressed in highly sensitive samples while resistant samples have little or no expression. Figure was created with BioRender

apoptosis $^{[154]}$. In contrast to the BCL2 Gly101Val mutation, which would be expected to affect only drugs that bind BCL2, BAX mutations would be expected to confer resistance to a wide variety of agents that activate the intrinsic apoptotic pathway. Another preclinical study using a genome-wide CRISPR/Cas9 screen in AML cell lines identified BAX, along with TP53 and PMAIP1, as genes whose inactivation results in venetoclax resistance ${ }^{[155]}$.

A number of resistance mechanisms also involve alterations in mitochondrial metabolism. Amplifications of changes in energy metabolism as a consequence of mitochondrial macrostructure rearrangement also appear to contribute to venetoclax resistance. A genome-wide CRISPR-Cas9 knock-out screen in the AML cell line MOLM-13 identified the mitochondrial chaperonin CLPB as a determinant of venetoclax sensitivity ${ }^{[132]}$. Expression of CLPB was shown to be significantly higher in AML cells, even greater in cells resistant to venetoclax, which resulted in tighter mitochondrial cristae. Conversely, CLPB loss was shown to restore venetoclax sensitivity ${ }^{[132]}$. From a genome-wide CRISPR-Cas9 knock-out screen in a venetoclaxresistant MOLM-13 derivative, the top hits that restored venetoclax sensitivity (DAP3, MRPL54, MRPL17, and $R B F A$ ) pointed to inhibition of mitochondrial translation as a potential mechanism of sensitizing resistant cells to venetoclax ${ }^{[156]}$. Further studies with doxycycline and tedizolid, which pharmacologically inhibit mitochondrial translation, led to the suggestion that diminished mitochondrial protein synthesis leads to respiratory dysfunction, which activates an integrated stress response that overcomes the resistance ${ }^{[156]}$, possibly by upregulating the pro-apoptotic BCL2 family members NOXA (PMAIP1) and PUMA $(B B C 3)^{[157]}$.

Epigenetic changes also appear to contribute to venetoclax resistance. Mantle cell lymphomas that were resistant to single-agent venetoclax therapy exhibited TP53, SMARCA4, CELSR3, CCND1, and KMT2D alterations, and allele loss often correlated with super-enhancer remodeling at $18 \mathrm{q} 21^{[158]}$. Next-generation sequencing or whole exome sequencing of 29 of the 32 cases of AML enrolled in the phase II venetoclax monotherapy study suggested that $S R S F 2 / Z R S R 2$ and $I D H 1 / 2$ mutations may predict sensitivity to venetoclax therapy in $\mathrm{AML}^{[138,159]}$. The effect of $S R S F 2$ mutation on venetoclax sensitivity may be explained by the alternative splicing of genes involved in apoptotic pathways ${ }^{[160]}$. 
In summary, mechanisms of resistance to venetoclax monotherapy are varied, from mutation of the drug binding pocket of BCL2 itself, to amplification of parallel anti-apoptotic signaling pathways, changes in energy metabolism, and epigenetic alterations.

\section{COMBINATION THERAPY WITH HYPOMETHYLATING AGENTS AND VENETOCLAX}

\section{Mechanism of action}

Combination therapy is employed to increase treatment efficacy beyond the action of a single agent, avoid dose-dependent adverse events, and evade potential mechanisms of resistance. With these goals in mind, the combination of venetoclax and HMAs was explored as a potential drug combination in preclinical studies. Treament of clinical AML samples initially ex vivo revealed synergy, at low nanomolar concentrations, between azacitidine and venetoclax ${ }^{[161,162]}$. Azacitidine treatment in AML cell lines was also shown to cause several pro-apoptotic changes, including a decrease in MCL1 protein levels ${ }^{[163,164]}$ and an increase in NOXA through activation of the integrated stress respons ${ }^{[157]}$. Combination therapy with azacitidine and $\mathrm{ABT}-737$, an inhibitor of $\mathrm{BCL} 2, \mathrm{BCLX}_{\mathrm{L}}$, and BCLW, not only displayed synergistic killing of AML cells but also decreased tissue invasion of leukemic cells in vivo, thus dampening a potential niche microenvironment-based evasion mechanism of resistance in $\mathrm{AML}^{[164]}$. Other preclinical studies have shown that the HMA/BCL2 inhibitor combination decreases oxidative phosphorylation and avoids genomic amplifications that reduce venetoclax monotherapy-induced energetic stress ${ }^{[165]}$. The HMA/ venetoclax combination was made even more attractive by the observation that the cytotoxic synergy occurs preferentially in neoplastic cells while sparing normal hematopoietic cells ${ }^{[166]}$.

Based on these preclinical findings, DiNardo et al. ${ }^{[19]}$ evaluated the safety and efficacy of the combination of azacitidine or decitabine with venetoclax in previously untreated AML patients 65 years of age or older who were ineligible for conventional induction chemotherapy. The most common grade 3 and 4 adverse events included neutropenic fever, pneumonia, leukopenia, neutropenia, anemia, and thrombocytopenia ${ }^{[19]}$. With a median time on study of $\sim 9$ months and a median duration of follow-up of $\sim 15$ months, the CR/ CRi rate was $67 \%$ and the overall leukemia response rate, including patients with partial response and morphologically leukemia free state, was $83 \%{ }^{[19]}$. Median overall survival was not reached at the time of the initial report ${ }^{[19]}$. Very similar results were observed in the phase III study of azacitidine and venetoclax in treatment-naïve AML patients ineligible for standard induction therapy ${ }^{[28]}$. Based on the phase II and III HMA/venetoclax results, as well as a phase II study of LDAC that also showed an increased CR/CRi rate and relapse-free survival compared to LDAC alone ${ }^{[20]}$, the combination of venetoclax with HMA or LDAC was approved by the U.S. FDA for the treatment of elderly or medically unfit patients with AML.

\section{Resistance to combination therapy}

The phase II HMA/venetoclax trial ${ }^{[19]}$ and the phase III azacitidine/venetoclax trial ${ }^{[28]}$ both indicate that $1 / 3$ of patients with newly diagnosed AML fail to achieve a CR or CRi with this therapy ${ }^{[1,28]}$ This high rate of treatment failure has prompted investigation into mechanisms of resistance to the combination.

Based on the mechanism of action of HMAs and venetoclax, it is logical that resistance might involve changes in BCL2 family members. Results of Pei et al. ${ }^{[167]}$ suggest that resistance to the azacitidine/ venetoclax doublet is mediated by the presence of monocytic AML cells, which upregulate MCL1 to evade BCL2 blockade and relieve mitochondrial energetic stress. These monocytes, which lose BCL2 expression and preferentially rely on MCL1 for survival, show outgrowth in relapsed/refractory AML and have a distinct immunopathogenic signature (CD 45-bright/SSC $\left.\mathrm{Sigh}^{\text {he }} / \mathrm{CD} 17^{-} / \mathrm{CD} 11 \mathrm{~b}^{+} / \mathrm{CD} 68^{+}\right)$that might allow early detection and therapeutic decision making ${ }^{[167]}$. Additional analysis showed that AML with monocytic differentiation (previously called M5 AML under the French-American-British classification system) had little or no response to the combination of azacitidine and venetoclax ${ }^{[167]}$. 
Another approach to understanding resistance has involved genomic characterization of AMLs that exhibit sensitivity vs. resistance. Through genomic analysis of AMLs treated on studies with venetoclax-based combinations, DiNardo et al. ${ }^{[168]}$ found that higher response rates and durable remissions were associated with NPM1 or IDH2 mutations. AMLs that did not respond to venetoclax-based combination therapy (primary resistance) or initially responded and then relapsed (adaptive or secondary resistance) had new or expanded clones with activating mutations of FLT3 or $R A S^{[168]}$. The variety of mutations occurring in different kinase pathways (e.g., FLT3-TKD, FLT3 N676, RAS, or CBL among others) and the increase in tumor heterogeneity following treatment indicate that resistance is likely driven by an evolving genetic diversity in the cell pool rather than a single dominant gatekeeper mutation. Genomic changes between diagnosis and relapse involved mutations in a variety of pathways, including kinase signaling such as FLT3ITD, NRAS, and JAK1 mutations; alternative RNA splicing due to mutations in U2AF1, U2AF2, SRSF2, and ZRSR2; cancer-related transcription factors, including IKZF1, SETBP 1, RUNX1, and STAT5A; tumor suppressors such as TP53 and WT1; and epigenetic modifiers such as BCOR and CREBBP ${ }^{[169]}$. The observed increase in AML cells harboring a FLT3-ITD mutation following treatment may indicate a clonal selection in which a small pool of FLT3-ITD cells are able to selectively withstand treatment and repopulate the marrow. The addition of inhibitors able to target mutated FLT3 such as sorafenib or midostaurin to the HMA/venetoclax combination treatment may help to combat this particular form of resistance.

While some of these mechanisms of resistance can potentially be targeted therapeutically (e.g., FLT3 mutation or even possibly TP53 mutation), others such as monocytic differentiation are more difficult to directly address pharmacologically. Accordingly, targeting a more general mechanism of resistance that is not usually dependent on specific genetic mutations may be of clinical utility. AML cells take advantage of stromal-dependent pro-survival signals to create a permissive niche within the bone marrow microenvironment via interactions between upregulated cell surface receptors, including very late antigen-4 (VLA-4), CD44, E-selectin ligand-1, and CD98, with adhesion molecules, including vascular cell adhesion molecule-1, fibronectin, hyaluronan, osteopontin, selectins, and integrins. This niche is favorable for the maintenance and progression of chemotherapy-resistant disease ${ }^{[170,171]}$. This mechanism of resistance, although less specific to the topic of this review, may be potentially modified or targeted; treatment with anti-VLA-4 antibodies and cytarabine improves survival in AML mouse models relative to cytarabine alone ${ }^{[172]}$. Additionally, patients with VLA-4-negative AML have a more favorable prognosis ${ }^{[172]}$.

Refined understanding of molecular determinants of sustained response, disease relapse, and secondary resistance to venetoclax-based combination therapy will undoubtedly help to guide future strategies for: (1) monitoring disease status; and (2) devising effective maintenance or salvage therapies. Multiple venetoclax-based combinations are currently being tested with the goal of circumventing drug resistance. These agents added to the HMA/venetoclax doublet include: a combination of cladribine and low-dose cytarabine, the NEDD8-actviating enzyme inhibitor pevonedistat, the anti-CD33 antibody/calicheamicin conjugate gemtuzumab ozogamicin, MDM2 inhibitors, and the anti-programmed death ligand-1 (PDL-1) antibody avelumab ${ }^{[173]}$. How safe and effective any of these strategies are remains to be determined. Despite the relatively high response rates with HMA/venetoclax combinations in patients newly diagnosed with AML, the fact that most responders relapse despite ongoing therapy further underlines the importance of understanding the mechanisms of acquired resistance ${ }^{[19,28]}$. Other outstanding questions include the optimal duration of therapy with the HMA/venetoclax doublet in responders, the effects of treatment interruption or discontinuation on long-term disease control, and the efficacy of the HMA/venetoclax doublet when reintroduced at the time of relapse.

\section{CONCLUSION}

The HMA/venetoclax combination represents are major advance for AML patients who previously fared poorly with conventional induction chemotherapy. As this combination is increasingly used, studies 
evaluating the causes of loss of response or relapse in clinical samples are needed to elucidate the patterns and mechanisms of resistance. It also remains crucial to explore modified dosing schedules for HMAs as a strategy to avoid acquired HMA resistance based on the results of recent studies with single-agent decitabine and azacitidine.

\section{DECLARATIONS}

\section{Authors' contributions}

Conducted literature review and wrote first draft: Saliba AN, John AJ

Edited manuscript: Saliba AN, John AJ, Kaufmann SH

\section{Availability of data and materials}

Not applicable.

\section{Financial support and sponsorship}

This work was in part by a grant from the NIH (R01 CA225996 to S.H.K.) and a fellowship to John AJ from the Mayo Foundation for Education and Research.

\section{Conflicts of interest}

All authors declared that there are no conflicts of interest.

\section{Ethical approval and consent to participate}

Not applicable.

\section{Consent for publication}

Not applicable.

\section{Copyright}

(c) The Author(s) 2021.

\section{REFERENCES}

1. Siegel RL, Miller KD, Jemal A. Cancer statistics, 2020. CA Cancer J Clin 2020;70:7-30.

2. Löwenberg B, Ossenkoppele GJ, van Putten W, et al; Dutch-Belgian Cooperative Trial Group for Hemato-Oncology (HOVON), German AML Study Group (AMLSG), Swiss Group for Clinical Cancer Research (SAKK) Collaborative Group. High-dose daunorubicin in older patients with acute myeloid leukemia. N Engl J Med 2009;361:1235-48.

3. Prébet T, Boissel N, Reutenauer S, et al; Acute Leukemia French Association, Groupe Ouest-Est des leucémies et autres maladies du sang (GOELAMS), Core Binding Factor Acute Myeloid Leukemia (CBF AML) intergroup. Acute myeloid leukemia with translocation (8;21) or inversion (16) in elderly patients treated with conventional chemotherapy: a collaborative study of the French CBF-AML intergroup. $J$ Clin Oncol 2009;27:4747-53.

4. Wahlin A, Markevärn B, Golovleva I, Nilsson M. Prognostic significance of risk group stratification in elderly patients with acute myeloid leukaemia. Br J Haematol 2001;115:25-33.

5. Farag SS, Archer KJ, Mrózek K, et al; Cancer and Leukemia Group B 8461. Pretreatment cytogenetics add to other prognostic factors predicting complete remission and long-term outcome in patients 60 years of age or older with acute myeloid leukemia: results from Cancer and Leukemia Group B 8461. Blood 2006;108:63-73.

6. Grimwade D, Walker H, Harrison G, et al; Medical Research Council Adult Leukemia Working Party. The predictive value of hierarchical cytogenetic classification in older adults with acute myeloid leukemia (AML): analysis of 1065 patients entered into the United Kingdom Medical Research Council AML11 trial. Blood 2001;98:1312-20.

7. Estey E. Acute myeloid leukemia and myelodysplastic syndromes in older patients. J Clin Oncol 2007;25:1908-15.

8. Krug U, Büchner T, Berdel WE, Müller-Tidow C. The treatment of elderly patients with acute myeloid leukemia. Dtsch Arztebl Int 2011;108:863-70.

9. Othus M, Appelbaum FR, Petersdorf SH, et al. Fate of patients with newly diagnosed acute myeloid leukemia who fail primary induction therapy. Biol Blood Marrow Transplant 2015;21:559-64.

10. Petersdorf SH, Kopecky KJ, Slovak M, et al. A phase 3 study of gemtuzumab ozogamicin during induction and postconsolidation therapy in younger patients with acute myeloid leukemia. Blood 2013;121:4854-60. 
11. Grimwade D, Hills RK, Moorman AV, et al; National Cancer Research Institute Adult Leukaemia Working Group. Refinement of cytogenetic classification in acute myeloid leukemia: determination of prognostic significance of rare recurring chromosomal abnormalities among 5876 younger adult patients treated in the United Kingdom Medical Research Council trials. Blood 2010;116:354-65.

12. Bullinger L, Döhner K, Döhner H. Genomics of acute myeloid leukemia diagnosis and pathways. J Clin Oncol 2017;35:934-46.

13. Kantarjian H, Ravandi F, O’Brien S, et al. Intensive chemotherapy does not benefit most older patients (age 70 years or older) with acute myeloid leukemia. Blood 2010;116:4422-9.

14. Kantarjian H, O'brien S, Cortes J, et al. Results of intensive chemotherapy in 998 patients age 65 years or older with acute myeloid leukemia or high-risk myelodysplastic syndrome: predictive prognostic models for outcome. Cancer 2006;106:1090-8.

15. DiNardo CD, Stein EM, de Botton S, et al. Durable remissions with Ivosidenib in IDH1-mutated relapsed or refractory AML. $N$ Engl $J$ Med 2018;378:2386-98.

16. Stein EM, DiNardo CD, Fathi AT, et al. Molecular remission and response patterns in patients with mutant- $I D H 2$ acute myeloid leukemia treated with enasidenib. Blood 2019;133:676-87.

17. Stone RM, Mandrekar SJ, Sanford BL, et al. Midostaurin plus chemotherapy for acute myeloid leukemia with a FLT3 mutation. $N$ Engl $J$ Med 2017;377:454-64.

18. Bose P, Vachhani P, Cortes JE. Treatment of relapsed/refractory acute myeloid leukemia. Curr Treat Options Oncol 2017;18:17,

19. DiNardo CD, Pratz K, Pullarkat V, et al. Venetoclax combined with decitabine or azacitidine in treatment-naive, elderly patients with acute myeloid leukemia. Blood 2019;133:7-17.

20. Wei AH, Strickland SA Jr, Hou JZ, et al. Venetoclax combined with low-dose cytarabine for previously untreated patients with acute myeloid leukemia: results from a phase Ib/II Study. J Clin Oncol 2019;37:1277-84.

21. Quintás-Cardama A, Ravandi F, Liu-Dumlao T, et al. Epigenetic therapy is associated with similar survival compared with intensive chemotherapy in older patients with newly diagnosed acute myeloid leukemia. Blood 2012;120:4840-5.

22. Dombret H, Seymour JF, Butrym A, et al. International phase 3 study of azacitidine vs conventional care regimens in older patients with newly diagnosed AML with $>30 \%$ blasts. Blood 2015;126:291-9.

23. Cashen AF, Schiller GJ, O’Donnell MR, DiPersio JF. Multicenter, phase II study of decitabine for the first-line treatment of older patients with acute myeloid leukemia. J Clin Oncol 2010;28:556-61.

24. Kantarjian HM, Thomas XG, Dmoszynska A, et al. Multicenter, randomized, open-label, phase III trial of decitabine versus patient choice, with physician advice, of either supportive care or low-dose cytarabine for the treatment of older patients with newly diagnosed acute myeloid leukemia. J Clin Oncol 2012;30:2670-7.

25. Al-Ali HK, Jaekel N, Junghanss C, et al. Azacitidine in patients with acute myeloid leukemia medically unfit for or resistant to chemotherapy: a multicenter phase I/II study. Leuk Lymphoma 2012;53:110-7.

26. Cidado J, Boiko S, Proia T, et al. AZD4573 Is a Highly Selective CDK9 Inhibitor That Suppresses MCL-1 and Induces Apoptosis in Hematologic Cancer Cells. Clin Cancer Res 2020;26:922-34.

27. Richard-Carpentier G, DiNardo CD. Venetoclax for the treatment of newly diagnosed acute myeloid leukemia in patients who are ineligible for intensive chemotherapy. Ther Adv Hematol 2019;10:2040620719882822.

28. DiNardo CD, Jonas BA, Pullarkat V, et al. Azacitidine and venetoclax in previously untreated acute myeloid leukemia. $N$ Engl J Med 2020;383:617-29.

29. Braun T, Itzykson R, Renneville A, et al; Groupe Francophone des Myélodysplasies. Molecular predictors of response to decitabine in advanced chronic myelomonocytic leukemia: a phase 2 trial. Blood 2011;118:3824-31.

30. Pleyer L, Germing U, Sperr WR, et al. Azacitidine in CMML: matched-pair analyses of daily-life patients reveal modest effects on clinical course and survival. Leuk Res 2014;38:475-83.

31. Sekeres MA, Othus M, List AF, et al. Randomized phase II study of azacitidine alone or in combination with lenalidomide or with vorinostat in higher-risk myelodysplastic syndromes and chronic myelomonocytic leukemia: north american intergroup study SWOG S1117. J Clin Oncol 2017;35:2745-53.

32. Fenaux P, Mufti GJ, Hellstrom-lindberg E, et al. Efficacy of azacitidine compared with that of conventional care regimens in the treatment of higher-risk myelodysplastic syndromes: a randomised, open-label, phase III study. Lancet Oncol 2009;10:223-32.

33. DiNardo CD, Rausch CR, Benton C, et al. Clinical experience with the BCL2-inhibitor venetoclax in combination therapy for relapsed and refractory acute myeloid leukemia and related myeloid malignancies. Am J Hematol 2018;93:401-7.

34. Sorm F, Pískala A, Cihák A, Veselý J. 5-Azacytidine, a new, highly effective cancerostatic. Experientia 1964;20:202-3.

35. Gu X, Tohme R, Tomlinson B, et al. Decitabine- and 5-azacytidine resistance emerges from adaptive responses of the pyrimidine metabolism network. Leukemia 2020; doi: 10.1038/s41375-020-1003-x.

36. Qin T, Jelinek J, Si J, Shu J, Issa JP. Mechanisms of resistance to 5-aza-2'-deoxycytidine in human cancer cell lines. Blood 2009;113:659-67.

37. Hollenbach PW, Nguyen AN, Brady H, et al. A comparison of azacitidine and decitabine activities in acute myeloid leukemia cell lines. PLoS One 2010;5:e9001.

38. Leone G, D'Alò F, Zardo G, Voso MT, Nervi C. Epigenetic treatment of myelodysplastic syndromes and acute myeloid leukemias. Curr Med Chem 2008;15:1274-87.

39. Bird AP, Southern EM. Use of restriction enzymes to study eukaryotic DNA methylation. J Mol Biol 1978;118:27-47.

40. McGhee JD, Ginder GD. Specific DNA methylation sites in the vicinity of the chicken beta-globin genes. Nature 1979;280:419-20.

41. Desrosiers RC, Mulder C, Fleckenstein B. Methylation of Herpesvirus saimiri DNA in lymphoid tumor cell lines. Proc Natl Acad Sci U S A 1979;76:3839-43. 
42. Constantinides PG, Taylor SM, Jones PA. Phenotypic conversion of cultured mouse embryo cells by aza pyrimidine nucleosides. Dev Biol 1978;66:57-71.

43. Taylor SM, Jones PA. Multiple new phenotypes induced in and 3 T3 cells treated with 5-azacytidine. Cell 1979;17:771-9.

44. Constantinides PG, Jones PA, Gevers W. Functional striated muscle cells from non-myoblast precursors following 5-azacytidine treatment. Nature 1977;267:364-6.

45. Jones PA, Taylor SM. Cellular differentiation, cytidine analogs and DNA methylation. Cell 1980;20:85-93.

46. Veselý J. Mode of action and effects of 5-azacytidine and of its derivatives in eukaryotic cells. Pharmacol Therap 1985;28:227-35.

47. Stresemann C, Lyko F. Modes of action of the DNA methyltransferase inhibitors azacytidine and decitabine. Int J Cancer 2008;123:8-13.

48. Kuykendall JR. 5-azacytidine and decitabine monotherapies of myelodysplastic disorders. Ann Pharmacother 2005;39:1700-9.

49. Lee TT, Karon MR. Inhibition of protein synthesis in 5-azacytidine-treated HeLa cells. Biochem Pharmacol 1976;25:1737-42.

50. Lu LJ, Randerath K. Mechanism of 5-azacytidine-induced transfer rna cytosine-5-methyltransferase deficiency. Cancer Res 1980;40:2701-5.

51. Schaefer M, Hagemann S, Hanna K, Lyko F. Azacytidine inhibits RNA methylation at DNMT2 target sites in human cancer cell lines. Cancer Res 2009;69:8127-32.

52. Taylor SM, Jones PA. Mechanism of action of eukaryotic DNA methyltransferase. J Mol Biol 1982;162:679-92.

53. Santi DV, Norment A, Garrett CE. Covalent bond formation between a DNA-cytosine methyltransferase and DNA containing 5-azacytosine. Proc Natl Acad Sci U S A 1984;81:6993-7.

54. Christman JK, Schneiderman N, Acs G. Formation of highly stable complexes between 5-azacytosine-substituted DNA and specific non-histone nuclear proteins. Implications for 5-azacytidine-mediated effects on DNA methylation and gene expression. $J$ Biol Chem 1985;260:4059-68.

55. Ferguson AT, Vertino PM, Spitzner JR, et al. Role of estrogen receptor gene demethylation and DNA methyltransferase.DNA adduct formation in 5-aza-2'deoxycytidine-induced cytotoxicity in human breast cancer cells. J Biol Chem 1997;272:32260-6.

56. Oka M, Meacham AM, Hamazaki T, Rodić N, Chang LJ, Terada N. De novo DNA methyltransferases Dnmt3a and Dnmt3b primarily mediate the cytotoxic effect of 5-aza-2'-deoxycytidine. Oncogene 2005;24:3091-9.

57. Copeland RA, Olhava EJ, Scott MP. Targeting epigenetic enzymes for drug discovery. Curr Opin Chem Biol 2010;14:505-10.

58. Champion C, Guianvarc'h D, Sénamaud-Beaufort C, et al. Mechanistic insights on the inhibition of c5 DNA methyltransferases by zebularine. PLoS One 2010;5:e12388.

59. Chen L, MacMillan AM, Chang W, et al. Direct identification of the active-site nucleophile in a DNA (cytosine-5)-methyltransferase. Biochemistry 1991;30:11018-25.

60. Wilson VL, Jones PA, Momparler RL. Inhibition of DNA methylation in 11210 leukemic cells by 5-aza-2'-deoxycytidine as a possible mechanism of chemotherapeutic action. Cancer Res 1983;43:3493-6.

61. Bender CM, Zingg JM, Jones PA. DNA methylation as a target for drug design. Pharm Res 1998;15:175-87.

62. Muvarak NE, Chowdhury K, Xia L, et al. Enhancing the cytotoxic effects of PARP inhibitors with DNA demethylating agents - a potential therapy for cancer. Cancer Cell 2016;30:637-50.

63. Jüttermann R, Li E, Jaenisch R. Toxicity of 5-aza-2'-deoxycytidine to mammalian cells is mediated primarily by covalent trapping of DNA methyltransferase rather than DNA demethylation. Proc Natl Acad Sci U S A 1994;91:11797-801.

64. Stingele J, Bellelli R, Boulton SJ. Mechanisms of DNA-protein crosslink repair. Nat Rev Mol Cell Biol 2017;18:563-73.

65. Veselý J, Cihák A, Sorm F. Characteristics of mouse leukemic cells resistant to 5-azacytidine and 5-aza-2'-deoxycytidine. Cancer Res 1968;28:1995-2000.

66. Mortusewicz O, Schermelleh L, Walter J, Cardoso MC, Leonhardt H. Recruitment of DNA methyltransferase I to DNA repair sites. Proc Natl Acad Sci U S A 2005;102:8905-9.

67. Vispé S, Deroide A, Davoine E, et al. Consequences of combining siRNA-mediated DNA methyltransferase 1 depletion with 5-aza-2'deoxycytidine in human leukemic KG1 cells. Oncotarget 2015;6:15265-82.

68. Stein EM, DiNardo CD, Pollyea DA, et al. Enasidenib in mutant IDH2 relapsed or refractory acute myeloid leukemia. Blood 2017;130:722-31.

69. Savona MR, Odenike O, Amrein PC, et al. An oral fixed-dose combination of decitabine and cedazuridine in myelodysplastic syndromes: a multicentre, open-label, dose-escalation, phase 1 study. Lancet Haematol 2019;6:e194-203.

70. Garcia-Manero G, Griffiths EA, Steensma DP, et al. Oral cedazuridine/decitabine for MDS and CMML: a phase 2 pharmacokinetic/ pharmacodynamic randomized crossover study. Blood 2020;136:674-83.

71. Roboz GJ, Montesinos P, Selleslag D, et al. Design of the randomized, Phase III, QUAZAR AML Maintenance trial of CC-486 (oral azacitidine) maintenance therapy in acute myeloid leukemia. Future Oncol 2016;12:293-302.

72. Wei AH, Döhner H, Pocock C, et al. The quazar aml-001 maintenance trial: results of a phase iii international, randomized, double-blind, placebo-controlled study of cc-486 (oral formulation of azacitidine) in patients with acute myeloid leukemia (aml) in first remission. American Society of Hematology Washington, DC; 2019.

73. Claus R, Lübbert M. Epigenetic targets in hematopoietic malignancies. Oncogene 2003;22:6489-96.

74. Momparler RL, Rivard GE, Gyger M. Clinical trial on 5-AZA-2'-deoxycytidine in patients with acute leukemia. Pharmacol Therap 1985;30:277-86.

75. Rivard GE, Momparler RL, Demers J, et al. Phase I study on 5-aza-2'-deoxycytidine in children with acute leukemia. Leuk Res 1981;5:453-62.

76. Wijermans P, Lübbert M, Verhoef G, et al. Low-dose 5-aza-2'-deoxycytidine, a DNA hypomethylating agent, for the treatment of high- 
risk myelodysplastic syndrome: a multicenter phase II study in elderly patients. J Clin Oncol 2000;18:956-62.

77. Wijermans PW, Krulder JW, Huijgens PC, Neve P. Continuous infusion of low-dose 5-Aza-2'-deoxycytidine in elderly patients with highrisk myelodysplastic syndrome. Leukemia 1997;11:1-5.

78. Kantarjian H, Issa JP, Rosenfeld CS, et al. Decitabine improves patient outcomes in myelodysplastic syndromes: results of a phase III randomized study. Cancer 2006;106:1794-803.

79. Lübbert M, Suciu S, Baila L, et al. Low-dose decitabine versus best supportive care in elderly patients with intermediate- or high-risk myelodysplastic syndrome (MDS) ineligible for intensive chemotherapy: final results of the randomized phase III study of the European Organisation for Research and Treatment of Cancer Leukemia Group and the German MDS Study Group. J Clin Oncol 2011;29:1987-96.

80. Silverman LR, Demakos EP, Peterson BL, et al. Randomized controlled trial of azacitidine in patients with the myelodysplastic syndrome: a study of the cancer and leukemia group B. J Clin Oncol 2002;20:2429-40.

81. Karon M, Sieger L, Leimbrock S, et al. 5-azacytidine: a new active agent for the treatment of acute leukemia. Blood 1973;42:359-65.

82. Saiki JH, Bodey GP, Hewlett JS, et al. Effect of schedule on activity and toxicity of 5-azacytidine in acute leukemia: a southwest oncology group study. Cancer 1981;47:1739-42.

83. Fenaux P, Mufti GJ, Hellström-Lindberg E, et al. Azacitidine prolongs overall survival compared with conventional care regimens in elderly patients with low bone marrow blast count acute myeloid leukemia. J Clin Oncol 2010;28:562-9.

84. Harris NL, Jaffe ES, Diebold J, et al. The world health organization classification of neoplasms of the hematopoietic and lymphoid tissues: report of the Clinical Advisory Committee meeting--Airlie House, Virginia, November, 1997. Hematol J 2000;1:53-66.

85. Silverman LR, McKenzie DR, Peterson BL, et al; Cancer and Leukemia Group B. Further analysis of trials with azacitidine in patients with myelodysplastic syndrome: studies 8421, 8921, and 9221 by the Cancer and Leukemia Group B. J Clin Oncol 2006;24:3895-903.

86. Pleyer L, Burgstaller S, Girschikofsky M, et al. Azacitidine in 302 patients with WHO-defined acute myeloid leukemia: results from the Austrian Azacitidine Registry of the AGMT-Study Group. Ann Hematol 2014;93:1825-38.

87. Thépot S, Itzykson R, Seegers V, et al; Groupe Francophone des Myélodysplasies (GFM), Acute Leukemia French Association (ALFA); Groupe Ouest-Est des Leucémies Aiguës; Maladies du Sang (GOELAMS). Azacitidine in untreated acute myeloid leukemia: a report on 149 patients. Am J Hematol 2014;89:410-6.

88. Hummel-Eisenbeiss J, Hascher A, Hals PA, et al. The role of human equilibrative nucleoside transporter 1 on the cellular transport of the DNA methyltransferase inhibitors 5-azacytidine and CP-4200 in human leukemia cells. Mol Pharmacol 2013;84:438-50.

89. Wu P, Geng S, Weng J, et al. The hENT1 and DCK genes underlie the decitabine response in patients with myelodysplastic syndrome. Leuk Res 2015;39:216-20.

90. Brueckner B, Rius M, Markelova MR, et al. Delivery of 5-azacytidine to human cancer cells by elaidic acid esterification increases therapeutic drug efficacy. Mol Cancer Ther 2010;9:1256-64.

91. Camiener GW, Smith CG. Studies of the enzymatic deamination of cytosine arabinoside-I. Biochem Pharmacol 1965;14:1405-16.

92. Zauri M, Berridge G, Thézénas ML, et al. CDA directs metabolism of epigenetic nucleosides revealing a therapeutic window in cancer. Nature 2015;524:114-8.

93. Eliopoulos N, Cournoyer D, Momparler RL. Drug resistance to 5-aza-2'-deoxycytidine, 2',2'-difluorodeoxycytidine, and cytosine arabinoside conferred by retroviral-mediated transfer of human cytidine deaminase cDNA into murine cells. Cancer Chemother Pharmacol 1998;42:373-8.

94. Beauséjour CM, Eliopoulos N, Momparler L, Le NL, Momparler RL. Selection of drug-resistant transduced cells with cytosine nucleoside analogs using the human cytidine deaminase gene. Cancer Gene Ther 2001;8:669-76.

95. Valencia A, Masala E, Rossi A, et al. Expression of nucleoside-metabolizing enzymes in myelodysplastic syndromes and modulation of response to azacitidine. Leukemia 2014;28:621-8.

96. Qin T, Castoro R, El Ahdab S, et al. Mechanisms of resistance to decitabine in the myelodysplastic syndrome. PLoS One 2011;6:e23372.

97. Gruber E, Franich RL, Shortt J, Johnstone RW, Kats LM. Distinct and overlapping mechanisms of resistance to azacytidine and guadecitabine in acute myeloid leukemia. Leukemia 2020;34:3388-92.

98. Grant S, Bhalla K, Gleyzer M. Interaction of deoxycytidine and deoxycytidine analogs in normal and leukemic human myeloid progenitor cells. Leukemia Research 1986;10:1139-46.

99. Grant S, Bhalla K, Gleyzer M. Effect of uridine on response of 5-azacytidine-resistant human leukemic cells to inhibitors of de novo pyrimidine synthesis. Cancer Res 1984;44:5505-10.

100. Itzykson R, Kosmider O, Cluzeau T, et al; Groupe Francophone des Myelodysplasies (GFM). Impact of TET2 mutations on response rate to azacitidine in myelodysplastic syndromes and low blast count acute myeloid leukemias. Leukemia 2011;25:1147-52.

101. Bejar R, Lord A, Stevenson K, et al. TET2 mutations predict response to hypomethylating agents in myelodysplastic syndrome patients. Blood 2014;124:2705-12.

102. Traina F, Visconte V, Elson P, et al. Impact of molecular mutations on treatment response to DNMT inhibitors in myelodysplasia and related neoplasms. Leukemia 2014;28:78-87.

103. Cedena MT, Rapado I, Santos-lozano A, et al. Mutations in the DNA methylation pathway and number of driver mutations predict response to azacitidine in myelodysplastic syndromes. Oncotarget 2017;8:106948-61.

104. Coombs CC, Sallman DA, Devlin SM, et al. Mutational correlates of response to hypomethylating agent therapy in acute myeloid leukemia. Haematologica 2016;101:e457-60.

105. Ali A, Penneroux J, Dal Bello R Jr, et al. Granulomonocytic progenitors are key target cells of azacytidine in higher risk myelodysplastic syndromes and acute myeloid leukemia. Leukemia 2018;32:1856-60.

106. Treppendahl MB, Kristensen LS, Grønbæk K. Predicting response to epigenetic therapy. J Clin Invest 2014;124:47-55. 
107. Li LH, Olin EJ, Buskirk HH, Reineke LM. Cytotoxicity and mode of action of 5-azacytidine on 11210 leukemia. Cancer Res 1970;30:2760-9.

108. Cheng JX, Chen L, Li Y, et al. RNA cytosine methylation and methyltransferases mediate chromatin organization and 5-azacytidine response and resistance in leukaemia. Nat Commun 2018;9:1163.

109. Earnshaw WC, Martins LM, Kaufmann SH. Mammalian caspases: structure, activation, substrates and functions during apoptosis. Ann Rev Biochem 1999;68:383-424.

110. Taylor RC, Cullen SP, Martin SJ. Apoptosis: controlled demolition at the cellular level. Nat Rev Mol Cell Biol 2008;9:231-41.

111. Strasser A, Cory S, Adams JM. Deciphering the rules of programmed cell death to improve therapy of cancer and other diseases. EMBO J 2011;30:3667-83.

112. Czabotar PE, Lessene G, Strasser A, Adams JM. Control of apoptosis by the BCL-2 protein family: implications for physiology and therapy. Nat Rev Mol Cell Biol 2014;15:49-63.

113. Moldoveanu T, Follis AV, Kriwacki RW, Green DR. Many players in BCL-2 family affairs. Trends Biochem Sci 2014;39:101-11.

114. Llambi F, Moldoveanu T, Tait SW, et al. A unified model of mammalian BCL-2 protein family interactions at the mitochondria. Mol Cell 2011;44:517-31.

115. Andreeff M, Jiang S, Zhang X, et al. Expression of Bcl-2-related genes in normal and AML progenitors: changes induced by chemotherapy and retinoic acid. Leukemia 1999;13:1881-92.

116. Venditti A, Del Poeta G, Maurillo L, et al. Combined analysis of bcl-2 and mdr1 proteins in 256 cases of acute myeloid leukemia. Haematologica 2004;89:934-9.

117. Delbridge AR, Grabow S, Strasser A, Vaux DL. Thirty years of BCL-2: translating cell death discoveries into novel cancer therapies. Nat Rev Cancer 2016;16:99-109.

118. Cory S, Roberts AW, Colman PM, Adams JM. Targeting BCL-2-like Proteins to Kill Cancer Cells. Trends Cancer 2016;2:443-60.

119. Singh R, Letai A, Sarosiek K. Regulation of apoptosis in health and disease: the balancing act of BCL-2 family proteins. Nat Rev Mol Cell Biol 2019;20:175-93.

120. Merino D, Kelly GL, Lessene G, Wei AH, Roberts AW, Strasser A. BH3-mimetic drugs: blazing the trail for new cancer medicines. Cancer Cell 2018;34:879-91.

121. Tse C, Shoemaker AR, Adickes J, et al. Abt-263: a potent and orally bioavailable bcl-2 family inhibitor. Cancer Res 2008;68:3421-8.

122. Stilgenbauer S, Eichhorst B, Schetelig J, et al. Venetoclax in relapsed or refractory chronic lymphocytic leukaemia with $17 \mathrm{p}$ deletion: a multicentre, open-label, phase 2 study. Lancet Oncol 2016;17:768-78.

123. Wilson WH, O'connor OA, Czuczman MS, et al. Navitoclax, a targeted high-affinity inhibitor of BCL-2, in lymphoid malignancies: a phase 1 dose-escalation study of safety, pharmacokinetics, pharmacodynamics, and antitumour activity. Lancet Oncol 2010;11:1149-59.

124. Roberts AW, Seymour JF, Brown JR, et al. Substantial susceptibility of chronic lymphocytic leukemia to BCL2 inhibition: results of a phase I study of navitoclax in patients with relapsed or refractory disease. J Clin Oncol 2012;30:488-96.

125. Mason KD, Carpinelli MR, Fletcher JI, et al. Programmed anuclear cell death delimits platelet life span. Cell 2007;128:1173-86.

126. Souers AJ, Leverson JD, Boghaert ER, et al. ABT-199, a potent and selective BCL-2 inhibitor, achieves antitumor activity while sparing platelets. Nat Med 2013;19:202-8.

127. Vogler M, Dinsdale D, Dyer MJ, Cohen GM. ABT-199 selectively inhibits BCL2 but not BCL2L1 and efficiently induces apoptosis of chronic lymphocytic leukaemic cells but not platelets. Br J Haematol 2013;163:139-42.

128. Roberts AW, Davids MS, Pagel JM, et al. Targeting BCL2 with Venetoclax in relapsed chronic lymphocytic leukemia. $N$ Engl J Med 2016;374:311-22.

129. Roberts AW, Huang D. Targeting BCL2 With BH3 mimetics: basic science and clinical application of venetoclax in chronic lymphocytic leukemia and related B cell malignancies. Clin Pharmacol Ther 2017;101:89-98.

130. Pham TD, Pham PQ, Li J, Letai AG, Wallace DC, Burke PJ. Cristae remodeling causes acidification detected by integrated graphene sensor during mitochondrial outer membrane permeabilization. Sci Rep 2016;6:35907.

131. Lucantoni F, Düssmann H, Llorente-Folch I, Prehn JHM. BCL2 and BCL(X)L selective inhibitors decrease mitochondrial ATP production in breast cancer cells and are synthetically lethal when combined with 2-deoxy-D-glucose. Oncotarget 2018;9:26046-63.

132. Chen X, Glytsou C, Zhou H, et al. Targeting mitochondrial structure sensitizes acute myeloid leukemia to venetoclax treatment. Cancer Discov 2019;9:890-909.

133. Hanada M, Delia D, Aiello A, Stadtmauer E, Reed JC. Bcl-2 gene hypomethylation and high-level expression in b-cell chronic lymphocytic leukemia. Blood 1993;82:1820-8.

134. Calin GA, Dumitru CD, Shimizu M, et al. Frequent deletions and down-regulation of micro- RNA genes miR15 and miR16 at $13 \mathrm{q} 14$ in chronic lymphocytic leukemia. Proc Natl Acad Sci U S A 2002;99:15524-9.

135. Cimmino A, Calin GA, Fabbri M, et al. miR-15 and miR-16 induce apoptosis by targeting BCL2. Proc Natl Acad Sci U S A 2005;102:13944-9.

136. Anderson MA, Deng J, Seymour JF, et al. The BCL2 selective inhibitor venetoclax induces rapid onset apoptosis of CLL cells in patients via a TP53-independent mechanism. Blood 2016;127:3215-24.

137. Huemer F, Melchardt T, Jansko B, et al. Durable remissions with venetoclax monotherapy in secondary AML refractory to hypomethylating agents and high expression of BCL-2 and/or BIM. Eur J Haematol 2019;102:437-41.

138. Konopleva M, Pollyea DA, Potluri J, et al. Efficacy and biological correlates of response in a phase II study of venetoclax monotherapy in patients with acute myelogenous leukemia. Cancer Discov 2016;6:1106-17.

139. Tausch E, Close W, Dolnik A, et al. Venetoclax resistance and acquired BCL2 mutations in chronic lymphocytic leukemia. Haematologica 
2019;104:e434-7.

140. Birkinshaw RW, Gong JN, Luo CS, et al. Structures of BCL-2 in complex with venetoclax reveal the molecular basis of resistance mutations. Nat Commun 2019;10:2385.

141. Blombery P, Anderson MA, Gong JN, et al. Acquisition of the recurrent Gly101Val mutation in BCL2 confers resistance to venetoclax in patients with progressive chronic lymphocytic leukemia. Cancer Discov 2019;9:342-53.

142. Anderson MA, Tam C, Lew TE, et al. Clinicopathological features and outcomes of progression of CLL on the BCL2 inhibitor venetoclax. Blood 2017;129:3362-70.

143. Tessoulin B, Papin A, Gomez-Bougie P, et al. BCL2-family dysregulation in B-cell malignancies: from gene expression regulation to a targeted therapy biomarker. Front Oncol 2018;8:645.

144. Thijssen R, Slinger E, Weller K, et al. Resistance to ABT-199 induced by microenvironmental signals in chronic lymphocytic leukemia can be counteracted by CD20 antibodies or kinase inhibitors. Haematologica 2015;100:e302-6.

145. Guièze R, Liu VM, Rosebrock D, et al. Mitochondrial reprogramming underlies resistance to BCL-2 inhibition in lymphoid malignancies. Cancer Cell 2019;36:369-84.e13.

146. Choudhary GS, Al-Harbi S, Mazumder S, et al. MCL-1 and BCL-xL-dependent resistance to the BCL-2 inhibitor ABT-199 can be overcome by preventing PI3K/AKT/mTOR activation in lymphoid malignancies. Cell Death Dis 2015;6:e1593.

147. Hollands C. Strychnine poisoning. Vet Rec 1989;124:473.

148. Mazumder S, Choudhary GS, Al-Harbi S, Almasan A. Mcl-1 phosphorylation defines ABT-737 resistance that can be overcome by increased NOXA expression in leukemic B cells. Cancer Res 2012;72:3069-79.

149. Luedtke DA, Niu X, Pan Y, et al. Inhibition of Mcl-1 enhances cell death induced by the Bcl-2-selective inhibitor ABT-199 in acute myeloid leukemia cells. Signal Transduct Target Ther 2017;2:17012.

150. Niu X, Zhao J, Ma J, et al. Binding of released Bim to Mcl-1 is a mechanism of intrinsic resistance to ABT-199 which can be overcome by combination with daunorubicin or cytarabine in AML cells. Clin Cancer Res 2016;22:4440-51.

151. Lin KH, Winter PS, Xie A, et al. Targeting MCL-1/BCL-XL forestalls the acquisition of Resistance to ABT-199 in acute myeloid leukemia. Sci Rep 2016;6:27696.

152. Li Z, He S, Look AT. The MCL1-specific inhibitor S63845 acts synergistically with venetoclax/ABT-199 to induce apoptosis in T-cell acute lymphoblastic leukemia cells. Leukemia 2019;33:262-6.

153. Weiss J, Peifer M, Herling CD, Frenzel LP, Hallek M. Acquisition of the recurrent Gly101Val mutation in BCL2 confers resistance to venetoclax in patients with progressive chronic lymphocytic leukemia (Comment to Tausch et al.). Haematologica 2019;104:e540.

154. Beà S, Valdés-Mas R, Navarro A, et al. Landscape of somatic mutations and clonal evolution in mantle cell lymphoma. Proc Natl Acad Sci U S A 2013;110:18250-5.

155. Nechiporuk T, Kurtz SE, Nikolova O, et al. The TP53 apoptotic network is a primary mediator of resistance to BCL2 inhibition in AML cells. Cancer Discov 2019;9:910-25.

156. Sharon D, Cathelin S, Mirali S, et al. Inhibition of mitochondrial translation overcomes venetoclax resistance in AML through activation of the integrated stress response. Sci Transl Med 2019;11:eaax2863.

157. Jin S, Cojocari D, Purkal JJ, et al. 5-Azacitidine induces NOXA to prime AML cells for venetoclax-mediated apoptosis. Clin Cancer Res 2020;26:3371-83.

158. Zhao S, Kanagal-Shamanna R, Navsaria L, et al. Efficacy of venetoclax in high risk relapsed mantle cell lymphoma (MCL) - outcomes and mutation profile from venetoclax resistant MCL patients. Am J Hematol 2020;95:623-9.

159. Chyla B, Daver N, Doyle K, et al. Genetic biomarkers of sensitivity and resistance to venetoclax monotherapy in patients with relapsed acute myeloid leukemia. Am J Hematol 2018:E202-5.

160. Kim E, Ilagan JO, Liang Y, et al. SRSF2 mutations contribute to myelodysplasia by mutant-specific effects on Exon recognition. Cancer Cell 2015;27:617-30.

161. Bogenberger JM, Kornblau SM, Pierceall WE, et al. BCL-2 family proteins as 5-Azacytidine-sensitizing targets and determinants of response in myeloid malignancies. Leukemia 2014;28:1657-65.

162. Pan R, Hogdal LJ, Benito JM, et al. Selective BCL-2 inhibition by ABT-199 causes on-target cell death in acute myeloid leukemia. Cancer Discov 2014;4:362-75.

163. Bogenberger JM, Delman D, Hansen N, et al. Ex vivo activity of BCL-2 family inhibitors ABT-199 and ABT-737 combined with 5-azacytidine in myeloid malignancies. Leuk Lymphoma 2015;56:226-9.

164. Tsao T, Shi Y, Kornblau S, et al. Concomitant inhibition of DNA methyltransferase and BCL-2 protein function synergistically induce mitochondrial apoptosis in acute myelogenous leukemia cells. Ann Hematol 2012;91:1861-70.

165. Pollyea DA, Stevens BM, Jones CL, et al. Venetoclax with azacitidine disrupts energy metabolism and targets leukemia stem cells in patients with acute myeloid leukemia. Nat Med 2018;24:1859-66.

166. Jilg S, Hauch RT, Kauschinger J, et al. Venetoclax with azacitidine targets refractory MDS but spares healthy hematopoiesis at tailored dose. Exp Hematol Oncol 2019;8:9.

167. Pei S, Pollyea DA, Gustafson A, et al. Monocytic subclones confer resistance to venetoclax-based therapy in patients with acute myeloid leukemia. Cancer Discov 2020;10:536-51.

168. DiNardo CD, Tiong IS, Quaglieri A, et al. Molecular patterns of response and treatment failure after frontline venetoclax combinations in older patients with AML. Blood 2020;135:791-803.

169. Maiti A, Rausch CR, Cortes JE, et al. Outcomes of relapsed or refractory acute myeloid leukemia after frontline hypomethylating agent and venetoclax regimens. Haematologica 2020; doi: 10.3324/haematol.2020.252569. 
170. Pievani A, Biondi M, Tomasoni C, Biondi A, Serafini M. Location first: targeting acute myeloid leukemia within its niche. J Clin Med 2020;9:1513.

171. Jacamo R, Chen Y, Wang Z, et al. Reciprocal leukemia-stroma VCAM-1/VLA-4-dependent activation of NF- $\mathrm{B}$ mediates chemoresistance. Blood 2014;123:2691-702.

172. Matsunaga T, Takemoto N, Sato T, et al. Interaction between leukemic-cell VLA-4 and stromal fibronectin is a decisive factor for minimal residual disease of acute myelogenous leukemia. Nat Med 2003;9:1158-65.

173. Knight T, Edwards H, Taub JW, Ge Y. Evaluating venetoclax and its potential in treatment-naïve acute myeloid leukemia. Cancer Manag Res 2019;11:3197-213. 